\title{
MICROSPORIDIAL KERATOCONJUNCTIVITIS IN AIDS
}

\author{
P. J. McCLUSKEY ${ }^{1}$, P. V. GOONAN ${ }^{1}$, D. J. E. MARRIOTT ${ }^{2}$ and A. S. FIELD ${ }^{3}$ \\ Sydney, Australia
}

\begin{abstract}
SUMMARY
Microsporidia are rare human opportunistic pathogens that are now increasingly recognised in patients with AIDS, most commonly as an ocular or enteric pathogen. This paper reports a case of microsporidial keratoconjunctivitis in a patient with AIDS which responded to treatment with dibromopropamidine isethionate ointment. The clinical and laboratory features of microsporidial ocular infection are reviewed.
\end{abstract}

Microsporidial ocular infection is rarely encountered in humans. First recognised in 1973, only 3 patients with ocular microsporidial infection had been reported in the literature prior to $1990,{ }^{1-3}$ when 5 patients with AIDS and microsporidial keratoconjunctivitis were identified in the United States. ${ }^{4-6}$ This paper reports a further case of microsporidial keratoconjunctivitis in a patient with AIDS, and reviews the clinical and laboratory features of microsporidial ocular infection.

\section{CASE REPORT}

A 36-year-old homosexual Caucasian male was found to be HIV seropositive in 1986 . He developed persistent generalised lymphadenopathy and fevers in May 1988 and treatment with azidothymidine was commenced. The CD4 count at this time was $83 \times 10^{6}$ cells per litre. Recurrent perianal herpes simplex infection was treated with oral acyclovir and suppressive therapy with this drug was continued.

In November 1989 the patient noted a change in vision and examination revealed bilateral cytomegalovirus retinitis. Treatment with ganciclovir was instituted using a 14-day induction regimen followed by five times per week maintenance therapy. There was an incomplete response to therapy with persistent opacification and

From: Department of Ophthalmology, ${ }^{2}$ Department of Microbiology and ${ }^{3}$ Department of Anatomical Pathology, St Vincent's Hospital, Sydney, Australia.

Correspondence to: Dr. P. J. McCluskey, Laboratory of Ocular Immunology, School of Pathology, University of NSW, Kensington NSW 2033, Australia. slow progression of the lesions in each eye. Multiple nasal ulcers developed and progressed despite ganciclovir and multiple courses of antibiotics. Herpes simplex infection was diagnosed by immunofluorescence following biopsy of a nasal ulcer and an acyclovir-resistant strain was subsequently isolated. In January 1990 the patient received a 3-week course of induction therapy with foscarnet which resulted in resolution of both the nasal and retinal lesions. Maintenance therapy with ganciclovir was then reinstituted.

In March 1990 asymptomatic mild bilateral punctate epithelial keratopathy was noted at a routine ophthalmology review and treatment with ocular lubricants was given. Over the next 3 months the patient noted progressive photophobia, redness and discomfort. Examination revealed diffuse conjunctival injection, widespread punctate epithelial erosions, superficial punctate keratitis and superficial stromal corneal infiltrates (Fig. 1). There was no associated uveitis. The cytomegalovirus retinopathy remained in remission. Viral and bacterial cultures from the conjunctiva were negative. The patient was treated topically with broad spectrum antibiotics, acyclovir and lubricants without effect.

At this time a diagnosis of microsporidial infection was entertained and conjunctival and corneal scrapings and biopsies were performed. Microscopy of the scrapings revealed myriad intracellular and extracellular Grampositive spores consistent with microsporidia (Figs. 2-5). Electron microscopy of the corneal biopsy revealed the polar tubule pathognomonic of microsporidia. Ultrastructural features including a polar tubule of seven spirals, single nucleus in each spore, and aggregation of developing sporoblasts in plasmodia, enabled the diagnosis of infection caused by a microsporidian of the genus Encephalitozoon (Figs. 6 and 7).

The patient was treated with dibromopropamidine isethionate (Brolene eye ointment, May \& Baker) topically four times daily with marked symptomatic and clinical improvement. He died in October 1990 from fulminant AIDS dementia with no evidence of further progression of the keratoconjunctivitis. 


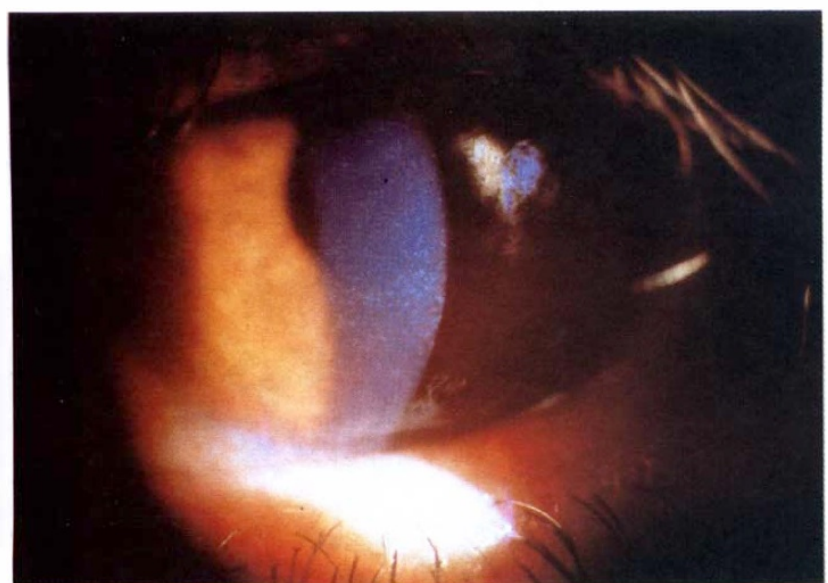

Fig. 1. Severe superficial punctate keratitis and punctate epithelial erosions associated with superficial stromal infiltrates.

\section{DISCUSSION}

Microsporidia are obligate intracellular spore-forming protozoa first identified in $1857 .^{7}$ They are members of the phylum Microspora, which contains 80 genera and over 700 species, and infect a wide range of vertebrates and invertebrates. Within this phylum is the order Microsporida, which contains the genera Nosema, Encephalitozoon, Pleistophora, Enterocytozoon and Microsporidium, the five genera known to be pathogenic to humans. Microsporida is often used as a descriptive term for these genera, and microsporidiosis to describe diseases caused by Microsporidia. Human microsporidial infection was first recognised in $1959^{8}$ and was first recognised in patients with HIV infection in 1985 as a cause of chronic diarrhoea and malabsorption. ${ }^{9}$ It has since been reported as a pathogen in a number of situations including myositis, hepatitis, peritonitis and keratoconjunctivitis. ${ }^{10-12}$

The genera Nosema, Microsporidium and Encephalitozoon have been implicated in corneal disease with only Encephalitizoon spp. being identified in AIDS patients. In three of the patients with AIDS a new species, Encephalitozoon hellem, was identified using electrophoretic and immunological techniques. ${ }^{13,14}$ Nosema corneum was isolated from deep ulcers in the corneal stroma of an HIV-

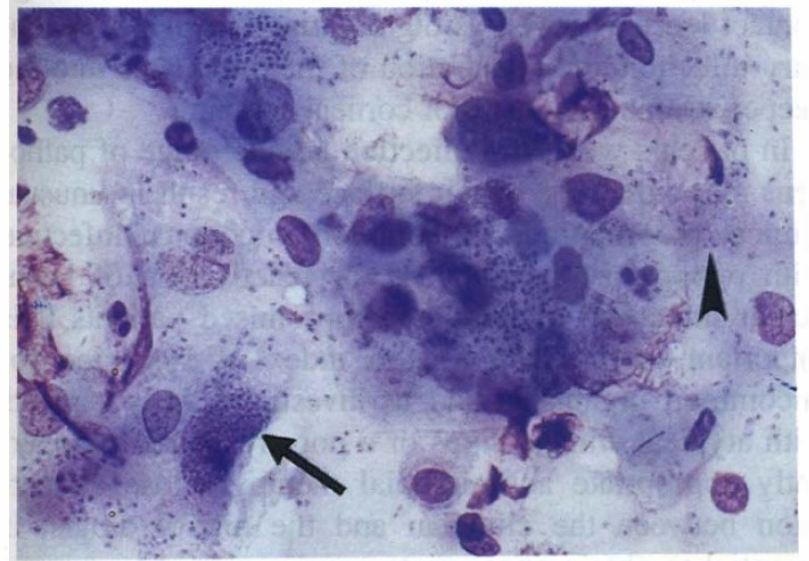

Fig. 2. Giemsa stain of corneal scraping showing plasmodia (arrow) within metaplastic squames and free spores (arrowhead) (Giemsa stain, ×600).

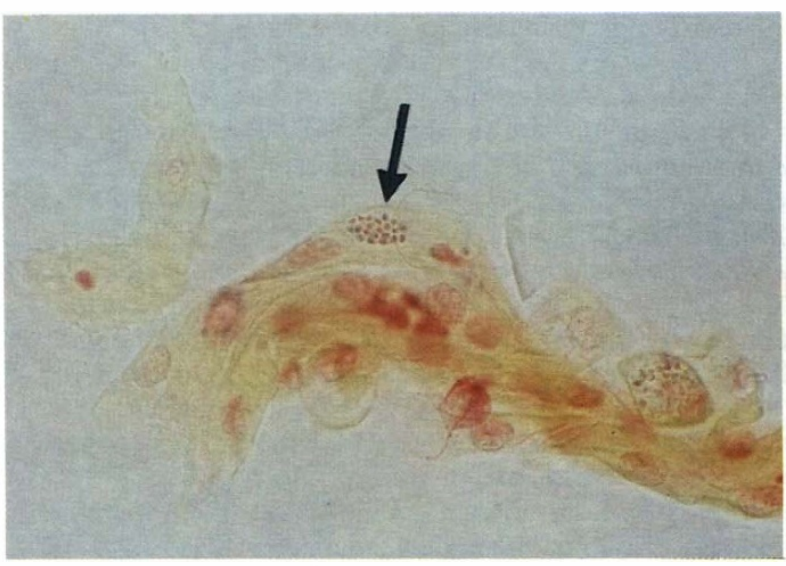

Fig. 3. Gram stain of corneal scraping showing plasmodia (arrow) within metaplastic squames (Gram stain, $\times 600$ ).

seronegative patient, ${ }^{3}$ while Encephalitozoon spp. were recovered from the superficial conjunctival and corneal epithelium of the 5 AIDS cases with keratoconjunctivitis. ${ }^{4-6}$ This may reflect a predilection for superficial structures, the manner of inoculation, or an early stage of infection. ${ }^{6}$ Evidence tends to support the superficial nature of Encephalitozoon infection.

The routes of transmission of human microsporidial infection are unknown but are thought to be either orofaecal or direct inoculation. Ocular disease is presumed to be acquired by direct inoculation. In our patient, as in earlier reports, there was a history of close contact with domestic animals such as cats and birds, which are known microsporidial hosts. Our patient had the characteristic clinical presentation of microsporidial ocular infection with progressive photophobia, ocular discomfort and redness, associated with conjunctival injection, punctate epithelial erosions, punctate epithelial keratitis and superficial stromal infiltrates. Corneal ulceration may occur and there may be a variable degree of stromal involvement, with superficial stromal focal infiltrates being most common. An associated anterior uveitis may be present. ${ }^{3}$ Involvement of other ocular structures has not been described.

Microsporidia are relatively poorly and variably stained by standard histochemical stains. ${ }^{15}$ Haematoxylin and

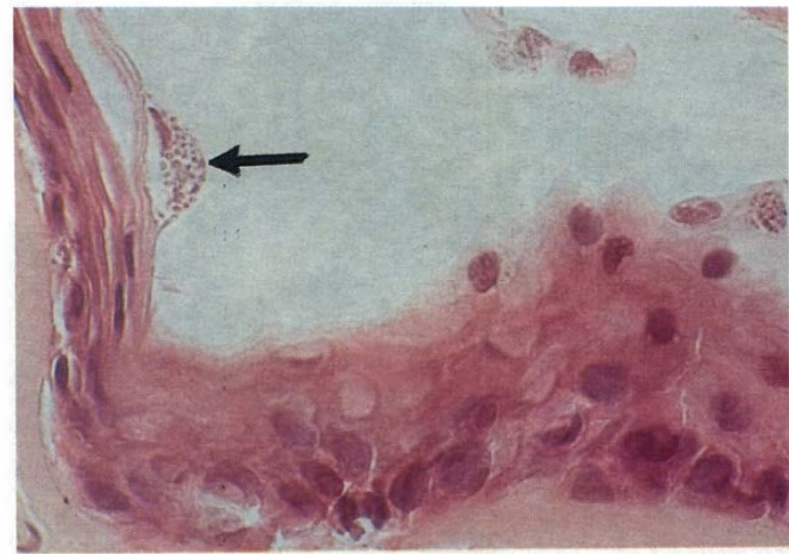

Fig. 4. Corneal biopsy showing plasmodia (arrow) within superficial keratinocytes of metaplastic squamous epithelium (haematoxylin and eosin, x600). 


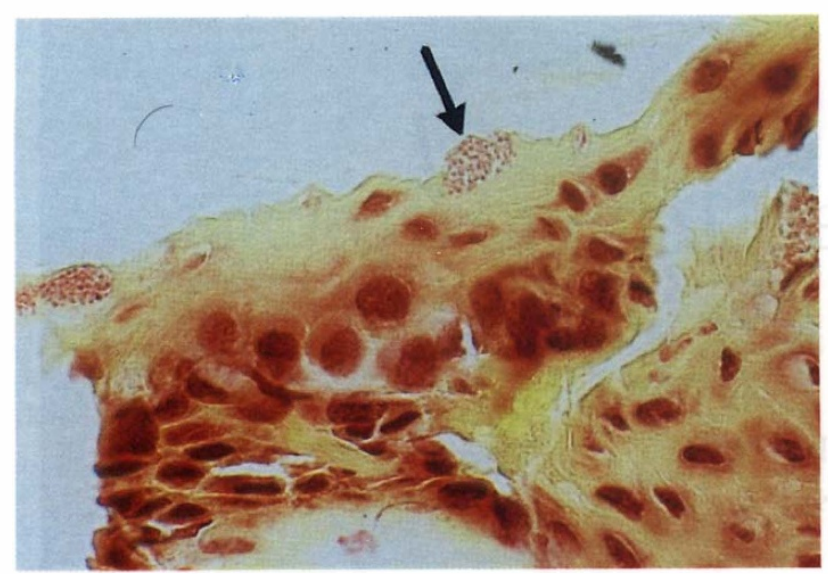

Fig. 5. Corneal biopsy showing plasmodia (arrow) within superficial keratinocytes of metaplastic squamous epithelium (Gram stain, ×600).

eosin, Giemsa, Gram stains and, in small bowel biopsies in our laboratory, Warthin-Starry stain, have been used to demonstrate the presence of Microsporidia in light microscope preparations. We have found the Warthin-Starry stain to be particularly useful. Encephalitozoon cuniculi spores are intensely Gram-positive in contrast to the variable Gram staining of spores belonging to other genera. ${ }^{16}$ The presence on light microscopy of a periodic acidSchiff (PAS) positive granule in the anterior end of mature spores is diagnostic for Microsporida. ${ }^{15}$ Fresh tissue squash preparations made from biopsy specimens may also be viewed directly by phase-contrast microscopy, where the spores are refractile and may be birefringent. ${ }^{15}$

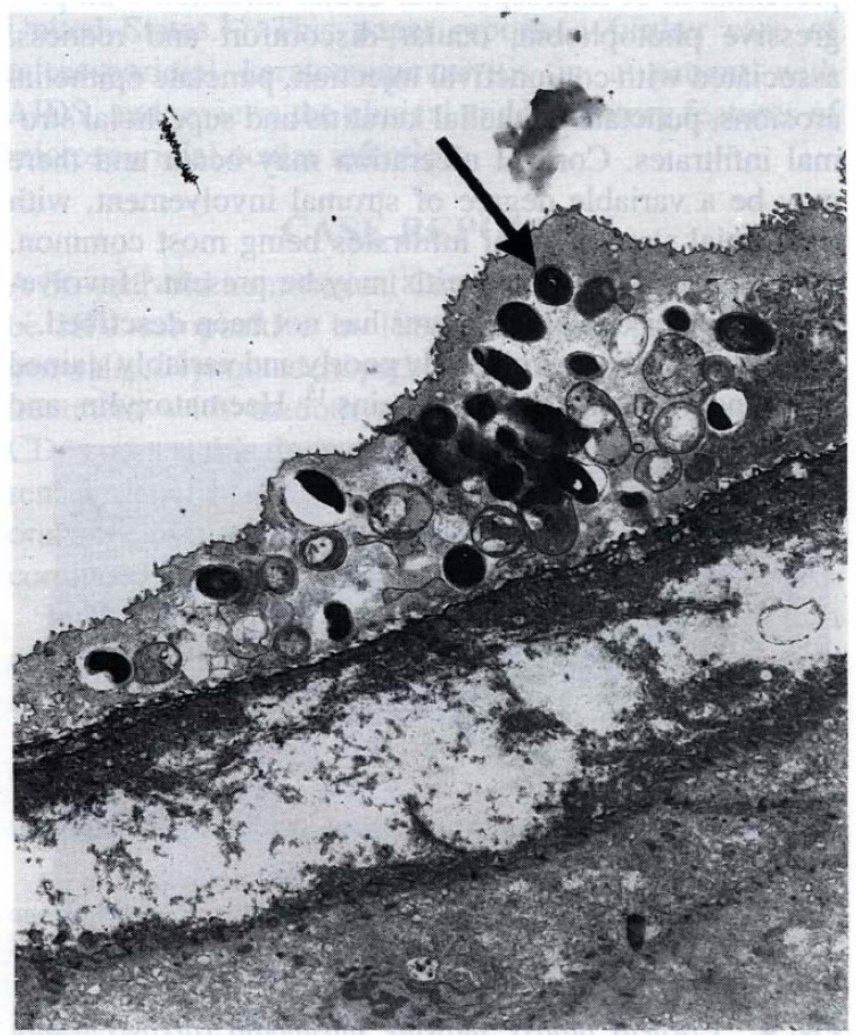

Fig. 6. Electron micrograph of sporoblasts (arrow) in superficial squamous cell of cornea $(\times 3000)$.

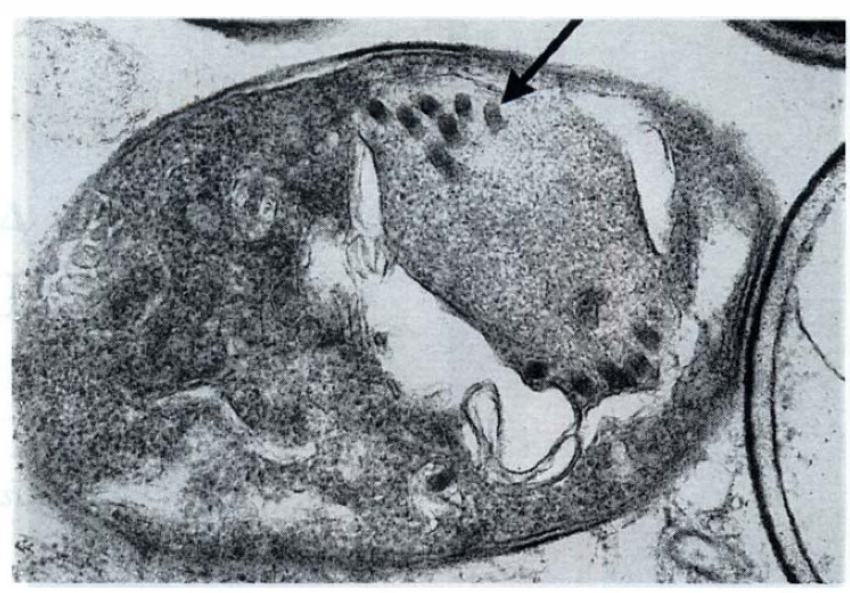

Fig. 7. Electron micrograph of spore showing its extrusion apparatus, the coiled polar tube (arrow) $(\times 38$ 000).

Organisms which may be confused morphologically with Microsporidia include Toxoplasma gondii, Leishmania spp., Histoplasma capsulatum and Cryptosporidia spp. ${ }^{3}$

Definitive diagnosis of microsporidial ocular infection requires examination of corneal or conjunctival biopsy by electron microscopy to demonstrate the pathognomonic coiled polar filament or tubule. Other features, such as the arrangement and complexity of the polar tubule, the number and size of nuclei and the location and relationship of the organism to the cytoplasm of the host cell, allow more precise species diagnosis. ${ }^{17}$ Immunological and biochemical techniques may also be useful in speciation. $^{15,16}$

There is no proven therapy for microsporidial infection. We achieved significant subjective improvement in our patient with topical dibromopropamidine isethionate (Brolene eye ointment) and no progression of disease occurred in the 3 months prior to death. Yee reported subjective improvement with debulking and topical neomycin/bacitracin/polymyxin B (Neosporin eye ointment, Calmic) and complete resolution with systemic itraconazole. ${ }^{6}$ Friedberg reported symptomatic improvement without change in the clinical signs in 1 of 3 patients with the use of topical sulfisoxazole diolamine. Friedberg also warned against the use of topical cortiosteroids or bandage contact lenses, as well as highlighting the risk of secondary infection and penetration of the organisms into the deeper stroma as a result of corneal scraping. ${ }^{5}$

In patients with HIV infection a wide range of pathogens may infect the ocular surface and result in unusual clinical presentations of common infections, infection with opportunistic pathogens, or reactivation of latent ocular infection. In immunocompromised patients it is important to maintain a high index of suspicion for uncommon organisms and to investigate fully patients with atypical clinical signs or a poor response to apparently appropriate antimicrobial therapy. Close cooperation between the clinician and the microbiologist is essential to obtain appropriate specimens and to process them correctly.

Key words: AIDS, Keratoconjunctivitis, Microsporidial infection. 


\section{REFERENCES}

1. Ashton N, Wirasinha PA. Encephalitozoonosis (Nosematosis) of the cornea. Br J Ophthalmol 1973;57:669-74.

2. Pinnolis M, Egbert PR, Font RL, Winter FC. Nosematosis of the cornea. Arch Ophthalmol 1981;99:1044-7.

3. Davis RM, Font RL, Keisler MS, Shadduck JA. Corneal microsporidiosis: a case report including ultrastructural observations. Ophthalmology 1990;97:953-7.

4. Lowder CY, Meisler DM, McMahon JT, Longworth DL, Rutherford I. Microsporidia infection of the cornea in a man seropositive for human immunodeficiency virus. Am J Ophthalmol 1990;109:242-4.

5. Friedberg DN, Stenson SM, Orenstein JM, Tierno PM, Charles NC. Microsporidial keratoconjunctivitis in acquired immunodeficiency syndrome. Arch Ophthalmol 1990;108: 504-8.

6. Yee RW, Tio FO, Martinez JA, Held KS, Shadduck JA, Didier ES. Resolution of microsporidial epithelial keratopathy in a patient with AIDS. Ophthalmology 1991;98: 196-201.

7. Nageli. Nosema bombycis. Bot Zeit 1857;15:760. Cited in: Canning EU, Lom J. The microsporidia of vertebrates, London: Academic Press, 1986; 15.

8. Matsubayashi H, Koike T, Mikata I, Takei H, Hagiwara S. A case of Encephalitozoon-like body infection in man. Arch Pathol 1959;67:181-7.

9. Modigliani R, Bories C, Le Charpentier Y, Salmeron M, Messing B, Galian A, et al. Diarrhoea and malabsorption in acquired immune deficiency syndrome: a study of four cases with special emphasis on opportunistic protozoan infestations. Gut 1985;26:179-87.

10. Ledford DK, Overman MD, Gonzalvo A, Cali A, Mester SW, Lockey RF. Microsporidiosis myositis in a patient with the acquired immunodeficiency syndrome. Ann Intern Med $1985 ; 102: 628-30$.

11. Terada S, Reddy KR, Jeffers LJ, Cali A, Schiff ER. Microsporidian hepatitis in the acquired immunodeficiency syndrome. Ann Intern Medern 1987;107:61-2.

12. Zender HO, Arrigoni E, Eckert J, Kapanci Y. A case of Encephalitozoon cuniculi peritonitis in a patient with AIDS. Am J Clin Pathol 1989;92:352-6.

13. Didier ES, Didier PJ, Friedberg DN, Stenson SM, Orenstein $\mathrm{JM}$, Yee RW, et al. Isolation and characterization of a new human microsporidian, Encephalitozoon hellem (n. sp.) from three AIDS patients with keratoconjunctivitis. J Infect Dis 1991;163:617-21.

14. Didier PJ, Didier ES, Orenstein JM, Shadduck JA. Fine structure of a new human microsporidian, Encephalitozoon hellem, in culture. J Protozool 1991;38:502-7.

15. Cali A, Owen RL. Microsporidiosis. In: Balows A, Hausler WJ, Ohashi M, Turano A, editors. The laboratory diagnosis of infectious diseases. Principles and practice. New York: Springer-Verlag, 1988;929-50.

16. Muscat I. Human microsporidiosis (editorial). J Infect 1990; 21:125-9.

17. Bryan RT. Microsporidia. In: Mandell GL, Douglas RG, Bennett JE, editors. Principles and practice of infectious diseases, 3rd edn. Edinburgh: Churchill Livingstone, 1990; $2130-4$. 